sensitive issues, such as medical discretion to disclose a familial genetic pattern when secrecy might entail grave harm to another person, the author is balanced but conservative. Some theological comment here is at its best in the book. (Joseph Fletcher is polarised with Paul Ramsey, it must be supposed, because Ramsey blew Fletcher's situation ethics out of the water. Now we can recall thankfully a large-hearted man who excited a generation, without taking his short cuts into seductive blind alleys - and let him pass).

The chapter on euthanasia, though organised on the same pattern as the others, calls for the most careful critical scrutiny. It ranges over the clinical diagnoses of different ways and stages of dying and death, from coma to brain stem death and the persistent vegetative state. Clinical diagnoses are properly descriptive, according to objective criteria. Moral and philosophical evaluation, as of "personhood", pertains to the duties and permissions attending the condition described; it has no place in the description itself. It is a little surprising, therefore, to find that the authority referenced for brain stem death is the writing of a neurologist and a philosopher - both eminent - rather than the published reports of the Conference of the Royal Medical Colleges and their Faculties, the body which has now reported also on the diagnosis of the persistent vegetative state.

The treatment of euthanasia is comprehensive and fair. One may wonder about the "long history" claimed for it: the classical allusions cited may refer more to suicide than to medically-induced death as we now discuss it. Events outstrip description. The position in the USA can now be updated from Trudo Lemmens, and in the Netherlands from Stef Gevers, in The British Medical Bulletin, 52.2, 1996. Advance directives are, in the UK, less helpful to those who want their doctors to kill them than is sometimes imagined: patients may validly exercise in writing only those powers which they have when face to face, namely to refuse unwanted treatment; they cannot bind a doctor to any procedure, particularly if that would conflict with good practice, conscience or the law. And euthanasia, in the UK, still stands without the law.

Here, then, is the material through which, in each subject, readers must think their way. It is a very satisfying book. The only grumble is against a new generation of publishers' editors

ideologically estranged from the facility of the common gender in the English language: to couple a plural pronoun with a singular subject (for example, "someone . . . themselves") is to compound unclarity with ugliness. Books worthy of the overseas market, as this one is, should carry authentic English with them.

G R DUNSTAN

Professor Emeritus of Moral and Social Theology,

King's College, London

\title{
A Decent Proposal: Ethical Review of Clinical Research
}

\section{Donald Evans and Martyn Evans, Chichester, John Wiley and Sons, 1996, 210 pages, £24.95.}

This volume would be a useful addition to the library of anyone interested in how ethical standards of health care research on people are maintained in the United Kingdom. It is particularly relevant to members of research ethics committees, whose task it is to review all research projects which are to use people as the subjects of their research.

The book begins with a discussion of the utilitarian tradition in the United Kingdom. In the context of research on humans, utilitarianism (to put it simplistically) justifies the action on the grounds that more people will benefit in the future than will be harmed for their sakes. The tradition is strong in this country; this has to be balanced by the careful protection of the research subject who may him/ herself be willing to be used as a means to someone else's ends. Research ethics committees are supposed to help create this balance.

It is very important that members of research ethics committees understand why research is designed as it is designed: only if one is armed with such understanding can one go on to assess the ethical merits of any research project. The chapter on research design and method gives an excellent explanation of this. The authors go on to discuss the vexed question of the differences between innovative treatment and research.

Next up for discussion is the balance that has to be achieved between risks and benefits. There is consideration of minimal risk and the difficulties and subjective interpretations of the con $\stackrel{1}{5}$ cept. The authors explain the ethica requirement for minimising risk: not: only do they explain it, they offer prac tical suggestions as to how to achieve it

There is an excellent discussion of consent, which correctly identifies the्छ. shortfalls in the notion of respect fo? autonomy. Any research ethics come mittee member reading this shoul\& understand why his or her role is not just a matter of ensuring that consen? procedures are correctly followed $\overrightarrow{\vec{\omega}}$ Not only can one never be quite sure of the success of the venture of informing a research subject and allowing a voluntary decision to be्W made, it remains true that there are some things which it is simply not right to ask people to do in the namee of research. There is a thorough dis음 cussion of the role of proxy and $\mathrm{a}_{-}$ wonderful quotation to precede itc "To you, Baldrick, the Renaissances was just something that happened to other people, wasn't it?" (Blackadder) $\overrightarrow{0}$ The whole book, I should say, is peppered with delightful quotations which are both funny and relevant. Io made the reading of it a great delighs and was a useful reminder of the neeक for a sense of humour: too ofteñ people whose role is to ask othe people to behave better are sadly lack ing in this faculty.

Chapters seven and following look at the research ethics committees themselves. The tension between the need to remain in touch with the needs and sensibilities of the ordinary people who tend to end up as research subjects, and the need to be properly informed and educated about the research ethics committees is recog nised. The key requirements for good ethical review practice are identified and explained as independence, com prehensiveness and thoroughness The authors look at the need for proos viding resources and training to help research ethics committees maintain their own standards of practice.

There is practical advice on what ar application form should look like: this is the form that the researcher seekingD ethical approval has to complete anc? submit to the committee. The case foro standardisation of application form $\bar{D}$ across the country is made. A chapte $\vec{P}$ is then devoted to legal issues, includ $\frac{\vec{P}}{\mathrm{D}}$ ing the question of whether members of research ethics committees are ever likely to have to defend their decision? in court.

The next two chapters consider the issue of multi-location research. The authors distinguish between reviewing 
the protocol as such and implementing the research locally. They propose that such a split is possible and give details of the solution to the difficulties multi-location researchers face. Their solution, which is the one which the authors designed on behalf of the Department of Health in 1992, involves three tiers of review: national (scientific review) regional and local. These proposals have been supplanted by more recent ones from the Chief Medical Officer; however, there are definite echoes of the original Swansea ideas in what is now to be implemented.

Finally: there is a rather nice chapter which looks at some options for future development, including the possibility of research ethics committees being put on a statutory basis; research ethics committees beginning to consider the economic implications of innovation; the development of hospital (practice) ethics committees, and finally the ethical review of health policy.

This is a useful book, and I would happily recommend it to anyone who sits on a research ethics committee, or who is thinking of sitting on one, and also to anyone who conducts research on humans. Donald Evans and Martyn Evans have provided us with a good addition to our libraries, and one which is made all the more enjoyable for the witty quotations throughout the book.

CLAIRE FOSTER

Centre of Medical Law and Ethics, King's College, London

\section{Society's Choices - Social and Ethical Decision Making in Biomedicine}

Edited by R E Bulger, E M Bobby and $\mathrm{H}$ V Fineburg, Washington DC, National Academy Press, 1995, $£ 48.95$

It is said that you cannot judge a book by its cover. Certainly this is true for the British reader of Society's Choices. It has the appearance of a weighty and scholarly study of the general principles of social and ethical decisionmaking in biomedicine. In fact it is the report of a committee commissioned to look at the specific problem of what structures should exist in the USA to address bioethical issues, published together with its background papers.
Such a report in the United Kingdom would be published in the sober livery of HMSO or similar bodies. It is the well-recognised ethnocentricity of American thinking, as well as the attractive and lively cover, which conceals this from the casual browser. In most of its five hundred pages it is assumed that this is solely a problem for the USA, and that a solution for that society is the only one for consideration.

The book analyses the role of various interest groups, of forces such as religious belief, and the various commissions and task forces which have addressed both specific issues and had more general remits over bioethical matters. Apart from a brief review of French, Danish and UK approaches, and one more detailed French case study in the background papers, the issues are, however, discussed entirely in the context of American institutions and social forces. An account of the role of the judiciary, the executive and the legislature in formulating health policy, for instance, considers only US examples. The role of these institutions in societies such as the countries of the European Union, where their constitutional relationships are very different, is not examined.

The book is thus of considerable value to anyone who is interested in the mechanisms by which bioethical issues have been addressed in the USA. In view of the importance of American thought in the development of bioethics, more people working in other societies may find this useful than its parochial character may suggest. Readers who are not American citizens will, however, find it hard to see its relevance to their very different social institutions. An exception to this general statement is a remarkable background paper on trust and honesty in science by Steven Shapin. This is a valuable contribution to the growing argument that virtue and shared moral values are an essential ingredient in any functioning social enterprise; an argument which has been advanced by moral philosophers such as Macintyre and Midgley. For most bioethicists however, this is a book to refer to as background to understanding American institutions and political processes rather than to study as a contribution to developing their own.

PETER D TOON GP, Hackney, London
Making Sense of Advance Directives (2nd ed)

Nancy King, Washington DC, Georgetown University Press, 1996, 286 pages, $£ 15.90 /$ US $\$ 19.95$.

What did Richard Nixon and Jacky Onassis have most in common? Both died in mid-1994 in the same New York hospital but according to Nancy King, the thing which caught public attention about both deaths was the hospital's compliance with their "living wills", which refused treatment. These so fascinated the public that the hospital switchboard was jammed for days with enquiries about "choice in dying". Beyond the American health system, however, the notion of people documenting in advance how medical decisions should be made at the end of their lives barely impinges on public consciousness. For the world at large, the level of fear of over-treatment is swamped by greater anxiety about getting too little - or inequitable access to - health care. Nor have comparable public figures, such as the Queen or Mrs Thatcher, displayed the same assiduity as the former US president in giving a lead in such advance planning. Could it be that Americans are simply less fearful of contemplating death . . . less thanatophobic than the rest of us?

On the contrary, one of the doubtlessly unintended themes of Nancy King's book is the contrast between the lukewarm public commitment to advance directives and the strong theoretical support for them from ethicists and law-makers. The book, which updates the 1991 version of the same title, seeks to convince clinicians and patients that they should give more serious attention to living wills. For, despite the publicity boost of the Nixon/Onassis demises, a dozen high-profile legal cases from Quinlan in 1976 to Cruzan in 1994, a plethora of books and articles (King lists over 200 reference titles), 89 federal acts on this issue and legislation requiring health facilities to promote advance directives in order to receive Medicare and Medicaid dollars, less than twenty per cent of Americans actually have one. This reluctance to think ahead about future mental incapacity and death spurs the author to suggest that "we could perhaps force a flowering of foresight" by legislating 